\title{
Study on Relative Problems about the Accountant Professional Judgment Ability
}

\author{
Xiling Dai \\ School of Business Administration, Shenyang University, Shenyang 110044, China \\ E-mail: sydxdxl@163.com
}

\begin{abstract}
With the promulgation and implementation of the new edition of accounting standard and the increasing complexity of the economic environment, the accountants' professional judgment ability should be further enhanced, and how to continually enhance the accountants' professional judgment ability has become into an important task in the accounting research. Based on that, starting from the implementation of the new edition of accounting standard, the basic connotation of the accountant professional judgment, and the actuality of the accountant professional judgment, the approaches and countermeasures to enhance the accountant professional judgment ability are researched in this article.
\end{abstract}

Keywords: New Edition of Accounting Standard, Accountant professional judgment, Enhancement

\section{The importance of accountant professional judgment ability}

The main attention of the financial accounting is to provide relative information for interested parties' decisions, which means the information provided by accountants must accord with two quality requirements, i.e. the pertinence and the reliability, and accountants should have higher professional competences, i.e. the professional judgment ability. Therefore, it is very important to enhance the quality of accounting information for enhancing accountants' professional judgment ability, especially under new edition of accounting standard, accountants should have strong professional judgment ability to deal with large numerous of accounting information. One characteristic of the new edition of accounting standard is that it transfers from past "rule orientation" to "principle orientation", which largely increases accountants' professional judgment space. The new edition of accounting standard could not include all possible instances and economic activities of enterprise, and there are not single and unchangeable accounting polices and accounting methods. In addition, the constitution of accounting standard is still far lagged from the economic development and the change of the trading form and balance form brought by the technical advancement, so for the running of the standard system, the judgment is very important. In daily economic items and trading accounting process, the grasp of the pertinence principle, the accrual basis principle, the revenue expenditure and the capital expenditure principle, the cautious principle, the realization principle, and the importance principle in the accounting standard should be realized by accountants' professional judgment.

\section{Concrete content and basic principles of the accountant professional judgment}

The accountant professional judgment means the process that accountants fully consider the actuality and future financing environment and management characteristics of enterprise, utilize the information materials, use their professional methods, logic analysis ability and professional experience, judge and select the principles, methods, and program when disposing daily accounting items and making financial reports, and facing uncertain accounting items, according to accounting law, standard, and traditions. The existence of the accountant professional judgment is because of the deficiency of the accounting theory and technology, the ambiguity of economic activity, and the uncertainty of future result. The accountant professional judgment runs through the whole accounting work, and is mainly embodied in following aspects.

\subsection{The embodiment of the accountant professional judgment ability in the accounting principle selection}

The accounting principle could instruct the accounting operation, but in the concrete accounting practice, accountants' professional judgment still should be depended. Because of the complexity and diversity of economic activity, when confirming, measuring, and opening out certain one accounting item in the accounting practice, the selection should be made among multiple accounting principles, but not only the single one principle judgment is difficult, but also certain conflict sometimes will exist among various accounting principles, such as the selection between the cautious principle and the consistency principle. Therefore, in concrete economic operations, how to select certain one accounting principle, and how to correctly deal with the using sequence of multiple principles must depend on accountants' professional judgment. 


\subsection{The embodiment of the accountant professional judgment ability in the accounting policy selection}

Accounting policies means the principles, bases, and accounting disposal methods used in the accounting confirmation, measurement, and report. Because of the complexity of economic items and the particularity of enterprise, the current accounting system allows enterprise to adopt different accounting disposal methods to same one economic item in certain range, and the selection standard of various methods is not be regulated, which requires accountants should use their own professional judgments in practical works to select concrete accounting disposal method in many selectable accounting disposal methods according to the concrete instance of the enterprise. For example, when the enterprise confirms the pricing method of stock, accountants can select proper method in the first-in first-out method, the weighted mean method, and the moving weighted average method, according to the concrete practice of the enterprise and the character of the stock. In the term of inflation, enterprises should select the first-in first-out method which could make the accounting information more really reflect the management of the enterprise.

\subsection{The embodiment of the accountant professional judgment ability in the accounting evaluation}

Accounting evaluation means enterprises' judgment to the trading or item with uncertain result based on the information which could be utilized recently. The change of accounting evaluation means that because the current status of capital and asset and the anticipated economic interest and obligation, the account value of capital or debt and the periodic consumed capital are also adjusted. Because of uncertain factors in the management activity, many financial report items could not be measured exactly, and they could only be estimated, and the evaluation process includes the judgment based on the information which could be acquired recently. Therefore, because of the uncertainty of economic activity, accountants have to reasonably predict and deduce the accounting information, which could make the accounting information more really reflect the status of enterprise. And the nicety of confirmation and measurement largely depends on accountants' professional judgment ability.

\section{Principles of the accountant professional judgment}

The accountant professional judgment is the economic management activity with strong professional characteristic and strong subjectivity, and any one judgment decision will influence interested parties' management decisions. Therefore, the accountant professional judgment should fully consider various aspects, and implement according to certain principle, which is not only an accountant's professional morality, but the embodiment of his accounting professional ability. And the judgment should be implemented according to following principles.

(1) Abiding by the accounting professional morality principle. Because of the subjectivity of professional judgment, if there is not the restriction of accounting professional morality, the reliability forming the accounting judgment will be discounted largely, which will directly threaten the quality of accounting information and the fairness and validity of the accounting report.

(2) Abiding by the fairness principle. In new edition of accounting standard, the fair value measurement is very important to enhance the quality of accounting information, which makes the measurement attribute be more scientific, and the reflection of capital and trading is more fair and correlative, and the time value of capital could be embodied. On the other hand, accountants should continually enhance their abilities to measure by the fair value.

(3) Abiding by relative laws and regulations, especially relative criterion principles of the accounting system. The existence of relative laws and regulations is to ensure the comparability of accounting information. Therefore, the accountant profession judgment is only implemented in the accounting laws and uniform accounting system of one country, or else, the accounting information will lose their values for the management decision-making.

\section{Problems existing in the accountant professional judgment in China}

Because of historical causes and subjective and objective factors, there is certain gap between the accountants' professional judgment ability and the new edition of accounting standard.

First, from historical causes, in the long-term accounting practice, because of the planning economy system and the official-cored system, China has gradually formed the tradition of rejecting judgment and advocating unification. In this instance, accountants lack in independent judgment wills and behaviors, and when they should make their own judgments, they all ask for instructors from leaders, and follow leaders' instruction. Facing increasingly complex economic environment large numerous of requirements of accounting professional judgment in new standard, this thinking tradition dealing with accounting affairs only according to the 
accounting system has not been adapted.

Second, on the one hand, though there are about 12 millions accountants in China, but their qualities are not consistent, and their whole level is lower, which seriously restrict the requirements of the new standard for accountants' professional judgment. On the other hand, even if accountants have the professional judgment consciousness, necessary professional knowledge, and practical experience, they will not certainly make high-quality professional judgment. As viewed from individual angle, part of accountants start from their individual interests, and make the behaviors disobeying the professional morality. At the same time, accountants' salary and treatment are decided by managers. So part of accountants will give up their professional morality and make unreasonable professional judgment because of managers' pressure.

\section{Approaches to enhance the accountant professional judgment ability}

\subsection{Strengthening the construction of the professional morality}

Validity and fairness are the basic requirements of financial report, and the most important in the corresponding accounting professional judgment standards is the honest principle. The professional morality is maintained in human consciousness and social consensus by depending on human faith, habit, and educational power, and it only occurs in the edge of the restriction of laws and standard for accountants' behaviors. New standard system endows large flexibility to accountants, so the professional morality construction should be further strengthened. The professional morality is the soul of accounting work, and it drives accountants to consciously reject various interested attractions, and void the influences of the power and bias, and ensure the accounting materials could subjectively and fairly reflect the financial status and management results of the accounting body. The accountants' honesty is the important part of the professional morality construction, and only honest accountants could subjectively and really implement the accounting, and offer correct accounting information.

\subsection{Correctly understanding and utilizing the professional judgment}

The accountant professional judgment should be the judgment in the frame of the accounting standard and regulations, but though it needs that accountants use their knowledge and experiences to make flexible judgment to some extent, but the accountant professional judgment must be based on the accounting laws and standards, and it only exerts the subjective initiative in the regulated range. Once this space is exceeded, and some operations which don't belong to the content of professional judgment could not be brought into the judgment range to juggle the accounting information, the accounting maneuver will occur.

\subsection{Grasping reasonable method and program of the accountant professional judgment}

The contents of the accounting professional judgment are very complex, and the complexity degrees are different. But the judgment profess all should follow some common approaches. To grasp reasonable professional judgment methods and programs will get twice the result with half the effort. This method principle is the soul of the problem. Only grasping good method and handling affairs according to procedure could better find and solve the problems of the accounting professional judgment.

\subsection{Strengthening the practice ability and paying attention to the accumulation of experiences}

The accounting professional judgment is the activity with strong practicalness, and accountants' professional judgment ability should be formed through continual training, practice, and long-term accumulations. As an accountant with high level, except for certain professional basic knowledge and higher theoretical quality, he should be good at the practice. In addition, in the practice, he should pay attention to the accumulation of experience, and for the accounting in the practice, he should learn to analyze, judge, and summarize, and cultivate good thinking habit. By continual accumulation, his accounting practice experiences will be more and more rich, and his accounting practice will be more quick, exact, harmonious, and flexible, and finally, a good circle will form.

\subsection{Establishing the concept of lifetime learning and continually enhancing the judgment ability}

The drastic competition of the modern society makes the lifetime learning concept become necessary, and the college accounting education is only the base to provide the lifetime learning for students, bot the end of learning. In the time of knowledge economy, because of continual innovation of enterprises, new economic operations will well up, and the accounting disposal and rules are innovated continually, which all requires accountants to refresh their knowledge, and continually enhance their professional judgment ability by the learning. Therefore, to establish the lifetime learning should be necessary quality for each one accountant.

\subsection{Perfecting the interior and exterior supervision systems}

The interior supervision system mainly means the interior accounting control system and the interior auditing 
committee in the enterprise, and enterprises should perfect the company governance structure, and fully exert the supervision right of the board of supervisors and independent director to the management and financial activity of company, and establish complete interior control system at the same time. For the exterior supervision system, on the one hand, enterprises should perfect the social supervision system taking the industrial self-discipline supervision as the core as soon as possible to restrain the supervise the accountant professional judgments, and on the other hand, governments should strengthen the exterior supervision of the government, take the independent auditing as the core, and especially strengthen the supervision and checking of the execution quality of rules and systems to restrain the accountants' professional judgment behaviors.

\section{References}

Li, Haiyan. (2005). Six Approaches to Enhance the Accountant Professional Judgment Ability. Friends of Accounting. No. 3.

Li, Zhengjun. (2006). Cultivating and Enhancing the Accountant Professional Judgment Ability. Chinese Agricultural Accounting. No. 9.

Wang, Wenyuan, Qu, Xihe \& Xu, Kun. (2008). Thinking about the Implementation of the New Accounting Standards and the Accountant Professional Judgment Ability. Friends of Accounting. No. 18.

Xue, Jing. (2008). How to Enhance the Accountant Professional Judgment Ability. Friends of Accounting. No. 23.

Zhang, Jiexin. (2009). Enhancing the Accountant Professional Judgment Ability under New Accounting Standards. Journal of Chongqing University of Science and Technology (Social Sciences Edition). No. 2. 